\title{
Dinamicidad en la poesía de Julles Supervielle. De la metáfora a la metamorfosis
}

\author{
M. Lourdes Carriedo López
}

El título de este trabajo pretende resumir el doble aspecto que en él se va a tratar, derivado de la constante esencial de la poesía de Jules Supervielle: su dinamicidad. Es precisamente esta característica la que potenciará su narrativa, condicionando la progresión actancial, espacial y temporal del poema, así como su poeticidad, contaminada finalmente del esquema narrativo anterior, por el que el proceso metafórico deriva hacia el proceso metamórfico.

El propio poeta hace alusión a esa introducción del esquema narrativo en el discurso poético:

«Je compte sur mon poème pour ordenner et faire chanter juste les images. Comme il baigne chez moi dans le rêve inérieur je ne crains pas de lui faire prendre parfois la forme d'un récit. La logique du conteur surveille le rêverie divagante du poète. $\mathrm{La}$ cóhésion de tout le poème loin d'en détruire la magie en consolide les assises (...). Le conte va directement d'un point à un autre alors que le poème, tel que je le conçois généralement, avance en cercles concentriques» ${ }^{1}$.

Palabras pertenecientes al texto metadiscursivo de En songeant à un art poétique que resumen perfectamente el quehacer poético de Jules Supervielle -poeta, novelista, dramaturgo cuya obra abarca la primera mitad de nuestro siglo-, y que al mismo tiempo ofrecen puntos de reflexión acerca de la posible -o, antes bien, imposible- distinción entre géneros.

Si el poema se compone de imágenes, éstas se presentan como representaciones mentales encarnadas en la palabra, asociadas en términos generales al mecanismo 
analógico o metafórico, que propicia sí la interrelación de un momento verbal y de un momento icónico, cobrando valor en el discurso a partir de una desviación respecto del contexto o respecto de la isotopía dominante, entendida ésta como redundancia sémica. La imagen no presenta, por lo tanto, un valor absoluto en sí misma, en su morfología, sino en función de su contexto y de las relaciones que se establezcan entre ella y las demás imágenes del texto. El estudio de su sintaxis conducirá al estudio de aquellos elementos que propician el paso de unas imágenes a otras, ya sea lógicamente, ya sea ilógicamente y en discontinuidad. Como es bien sabido, a partir de Rimbaud, de Lautréamont y sobre todo de Mallarmé, esta progresión se establece en discontinuidad, a partir del poder de figuración y de sorpresa de la imagen, enraizada siempre en lo más profundo del ser en virtud de su fundamento ontológico.

En el caso de Jules Supervielle no se trata tanto de ofrecer ese afloramiento desordenado del mundo interior, inconexo y fragmentario, como de organizar los haces de esas mismas imágenes en función de una lógica y de un orden, siempre bajo la supervisión de una mente ordenadora y lúcida. De ahí su relativo alejamiento de los surrealistas -para los que la discontinuidad es ley-y su acercamiento a poetas que siguen una tradición narrativa considerada ya como absoluta desde el predominio de los delirios rimbaldianos. Se deduce así la situación de nuestro poeta en el marco de la Literatura Francesa, constituyendo una de las grandes voces de la poesía moderna francesa, a mitad de camino entre las audacias surrealistas -sobre todo en lo que respecta al tratamiento «irracional» de la imagen- y el desarrollo discursivo y narrativo del poema, abandonado desde años atrás. En este sentido, Supervielle entraría en el grupo de los independientes o, mejor dicho, de los «inclasificables», al igual que Saint-John Perse o Pierre Reverdy, o Léon-PaulFrague, como apunta M. Raymond en De Baudelaire au surréalisme $e^{2}$.

El segundo punto que se plantea a partir del texto metadiscursivo leído es precisamente el del criterio preciso de ordenación de esas imágenes, que se deriva de la voluntad de organización del texto como «relato» (de ahí esa referencia a «la logique du conteun y a la «cohésión de tout le poème»). Ello supone la introducción de una progresión ordenada en función de unos ejes actancial, temporal y espacial, en definitiva, de una narrativa que coexistirá con esa redundancia tradicionalmente intrínseca al texto poético. En efecto, recordemos cómo los postulados jakobsonianos defendían esta característica como estrictamente poética, manifestándose en los diferentes niveles del texto: métrico, fónico, morfo-sintáctico y semántico. El poema quedaba entonces definido como una secuencia verbal en cuyo interior se repiten las misma relaciones en diferentes niveles. Ello enlaza efectivamente con la consideración tradicional del carácter estático de la poesía, que constituye la base de la distinción entre poesía y novela establecida, entre otros, por H. Bonnet en Roman et poésie. Essai sur l'esthétique des genres ${ }^{3}$.

${ }^{2}$ M. RAYMOND, De Baudelaire au surréalisme, Paris, Corti, 1940.

${ }^{3}$ BONNET, H. Roman et poésie. Essai sur l'esthétique des genres. Paris, Nizet, 1980. 
Sin embargo, cabe afirmar la existencia de una dinamicidad en el texto poético, ya sea de carácter anecdótico, ya sea de carácter semántico, o de ambos a la vez. Un poema predominantemente redundante como Le message de J. Prévert no deja de contarnos una historia. Por otra parte, es innegable el carácter semántico de esa dinamicidad en el poema Neiges de Saint-john Perse ${ }^{4}$ o en el Salut de Mallarmé, que tantos estudios críticos ha generado. En ellos, el análisis de la estructura metafórica del texto demuestra una progresión a pesar de la redundancia fónica o morfo-sintáctica, y el posible establecimiento de núcleos actanciales a lo largo del texto. En este sentido, todo poema se configura como trayecto a través de una sustancia lingüística, realizado por una fuerza actancial que puede presentar un carácter múltiple.

En este sentido, hemos de poner de relieve la última parte del texto metadiscurssivo citado anteriormente, centrándonos en el componente verbal: «le conte $v a$ directement: le poème avance en cercles concentriques». Va y avanza indican ya la existencia de una progresión, el hecho de que el punto de partida y el de llegada no sean los mismos, de que se produzcan un recorrido. Y éste no se producirá tan sólo de manera horizontal, no sólo en función del eje de sucesiones, sino también de manera vertical, en función del eje de simultaneidades, en función del espesor paradigmático conferido por el elemento analógico. Precisamente sea aquí donde resida la principal diferencia entre el texto poético y el texto narrativo, independientemente de su estructura prosódica o rítmica: aquel presenta un mayor espesor constituído por una mayor presencia de figuras de analogía que inciden en una mayor profundiad, que le confieren otro sentido, una aprehensión diferente de la realidad, así como un sincretismo expresivo conferido por la síntesis metafórica. Como dice J. C. Renard: «L'image, la figure, est beaucoup plus qu'une représentation: elle est aussi ce que définit le poème, ce qui donne au texte son sens» 5 .

Este conjunto de imágenes se engasta en la poesía superviliana en un esqueleto narratico que encauza y sustenta toda la estructura poética del poema, por lo que «la lógica del narrador controla la ensoñación incoherente del poeta».

De este modo, es posible encontrar en sus poemas un hilo lógico que confiere coherencia o, al menos, sirve de nexo de unión a las diferentes hiladas se imágenes que en él se vertebran. Ello supone la existencia de una dinámica conferida por una acción llevada a cabo por un sujeto agente ya personal, ya cósmico, ya encarnación mágica de las pulsiones interiores, como es el caso del papel actancial de Ullin en la quête de joie de Patrice de la Tour du Pin, o del ahogado o del vagabundo cósmico («le hors-venu») en el caso de Supervielle.

Así pues, el texto presenta una estructura narrativa, por la que se construye como dinamismo temporal que lleva la actante o fuerza actancial de un momento A inicial a un momento B», en el que ni el tiempo ni el espacio recorridos han de ser necesariamente referenciales, porque, como dice Laurent Jenny en «Le poétique et le narratif»: «ce qui

\footnotetext{
${ }^{4}$ Ver el estudio que realiza Javier del Prado en «Ecrit sur Neiges», Anuario de Estudios Filológicos, Universidad de Extramuda, Cáceres, 1988.
}

5 J. C. RENARD, Notes sur la poésie, Paris, Seuil, 1970, p. 49. 
fait l'originalité de la temporalité poétique, c'est qu'elle est exclusivament enchaînée à l'énonciation, sans jeu avec un temps référentiel, hors texte» 6 .

Se crea así la ficción, que en el poema configura un espacio referencial propio, generado exclusivamente por el texto. Se habla por ello del carácter estrictamente diegético de la poesía, creador de un universo propio en virtud de su metaforización y, por lo tanto, de su constante y sistemática transgresión del espacio referencial. Siguiendo las afirmaciones de E. Cardonne-Arlyck: «le poème, quand il dessine le devenir du sujet, quand donc il ébauche une histoire, est tout à la fois le lieu, le temps, l'origine et la fin de cette histoire, qu'il comprend intégralement» ${ }^{7}$.

El poema superviliano se construye, en efecto, como un «proceso orientado», autorreferencial, que podemos observar en tres poemas escogidos a lo largo de su obra, y que al mismo tiempo lustran la evolución experimentada por su poesía, que se configura como búsqueda sucesiva del mundo, de Dios y del hombre a través del lenguaje. Búsqueda que al mismo tiempo condiciona la evolución temática y simbólica de la obra.

Los tres poemas que elegimos como ejemplos ilustrativos de nuestra reflexiones son los siguientes: «Comme un boeuf bavant au labour» (Débarcadères, 1922), «Sans 'Dieu» (Leforçat innocent, 1930), «Quand le cerveau gît dans sa grotte» (Le corps tragique, 1959). (Ver anexos I, II, III).

El primero de ellos pertenece a uno de los primeros libros publicados por Supervielle, Débarcadères, en el que domina claramente la actancialidad cósmica.

El poema se construye en función de dos núcleos actanciales -entendidos como fuerzas temáticas impulsoras de la dinámica textual- en dialéctica:

-navío, que domina actancialmente toda la primera parte del poema, en los primeros veinte versos, dominados por el nivel asertivo.

-mar (versos 21-40), en los que predomina el nivel apelativo.

Fuerzas actanciales antagónicas cuya acción presenta como resultados esa «blessure blanche et bruissante», metáfora descriptiva de la estela marina en la que domina el semantismo de «desgarramiento», de «déchirure», constante que se reitera en los participios «déchirée», «déchiquetée», y que al mismo tiempo implicanuna solidificación del elemento acuático.

La dinámica textual se genera esencialmente por los verbos y los relatores espaciotemporales, que marcan una progresión:

-espacial: de la superficie marina al fondo del mar.

-temporal: paso del día a la noche, a través de los relatores temporales.

Es de destacar, asimismo, que los elementos verbales indican, por un lado, la progresión, referida esencialmente al navío: por otro, la periodicidad, la iteración del movimiento, a través sobre todo del microsegmento narrativo constituído por la acción de la ola, que nos revela una estructuración cíclica en el interior del propio poema, con dinámica de avance-retroceso: «palpe, éprouve, s'accroche, s'écarte».

${ }^{6}$ L. JENNY, «Le poétique et le narratif», in Poétique 28, Paris, Seuil, 1976, pág. 448.

${ }^{7}$ E. CARDONNE-ARLYCK, La métaphore raconte, Pratique de Julien Graco, Paris, Klinkcsieck, 1984. 
Estos microsegmentos contribuyen a crear puntos de huída, líneas tangenciales respecto al relato vertebral que llegan a cobrar autonomía propia, indicando en este caso el desarrollo completo de una acción iniciada y completada pero etemamente renovada (versos 3-12), de donde se desprende la constante de la permanencia en el cambio, que se confirma explícitamente en las proposiciones de relativo en apóstrofe: «qui ne puise en soi que ressemblances», «que s'essaie... », «vaine», cuyo elemento nuclear, «mar», simbolizará, por otra parte, el tema de la continuidad en el seno de la transformación continua.

Pero lo cierto es que el texto nos cuenta una «historia»: el avance desgarrador del navío por la línea horizontal de la superficie marina, solidificada en función del archisemema ${ }^{8}$ «dureza», y la descripción del poder de atracción y de succión hacia las profundidades de un mar personificado capaz de atraernos hasta lo más profundo. El tránsito entre una situación y otra se produce por medio de una imagen verticalizante, «vous tire par les pieds», hasta alcanzar el reino de la ausencia y de la nada («sans»), el reino del ahogado, uno de los grandes ejes actanciales no sólo de la poesía superviliana, sino también de sus cuentos (véase el cuento que desarrolla el núcleo narrativo contenido en el poema de idéntico título, «Le survivant»).

Si por relato se entiende la presentación de una serie de acontecimientos que se desarrollan en un marco espacio-temporal determinado, el poema que nos ocupa se estructura como tal, en función de una progresión en la redundancia anafórica de un espacio A a un espacio B, de un Tiempo A a un Tiempo B:

A. Avance diurno del navío por la superficie marina solidificada.

$A>B$ imagen verticalizante: elemento bisagra.

B. Profundidades marinas. Nocturnidad. Momento B en el que el poema nos aclara su propia dinámica profunda: la interrogación retórica plantea el eterno problema sobre el mundo que subyace en la poesía superviliana.

El avance en tensión de las dos fuerzas actanciales del poema se resuelve metafóricamente en el archisemema «esfuerzo», que se deduce ya de la comparación que abre el poema («comme un boeuf bavant au labour»), así como en el nivel fónico, por la aliteración de bilabiales sonoras $(/ \mathrm{b} /)$ y sordas $(/ \mathrm{p} /)$. Y avance con esfuerzo a través de lo duro, lo sólido, lo fijo, lo estático en consonancia con la temporalidad abolida por la similitud del instante (tiempo espacializado y congelado de «horizon que coïncide sans bavures/vibre d'un son identique»). Suspensión temporal no sólo expresada por la reiteración de instantes similares o por el movimiento continuado sin avance del mar, sino también implicado en ese presente de indicativo en el que el hic y el nunc pierden su concreción y atisban la eternidad.

Por su parte, las oraciones de relativo introducen generalmente el elemento descriptivo, ya sea de valor adjetival ya sea introduciendo determinaciones espaciales, pero en algunos casos suponen ciertamente una extensión discursiva del sustantivo, insertando una acción y una temporalidad en la «nominación»: «au choc de mon regard

\footnotetext{
${ }^{8}$ Entendemos por «archisemema» el resultado de la intersección de un conjunto dado de sememas.
} 
qui se sépare de moi», o «présence dure qui, la nuit, vous tire par les pieds. . .» oraciones de relativo que pueden introducir microsegmentos narrativos completos: «présence fixe où hier tomba un mousse détaché d'un cordage comme par un coup de fusil», única alteración temporal por la introducción de un tiempo verbal pasado. Lo mismo ocurre a partir del relativo anafórico «présence dure qui, la nuit. ..» donde se marca la transición entre espacios y tiempos cósmicos a partir del poder de absorción marina, imán hacia la muerte, hacia esa nada creada en ausencia que evidencia la interrogación retórica final.

Esta interrogación va rápidamente a convertirse en una búsqueda del sentido humano, no sólo a través del ámbito cósmico físico sino también metafísico. Surge así una dinámica de búsqueda impulsada por el deseo -psíquico, metafísico- de conocimiento, búsqueda concretada espacialmente por la exploración de lo desconocido. De ahí brota el poema «Sans Dieu» perteneciente a Le forçat innocent, texto de 1930, a partir del cual el yo deja de manifestarse tímidamente para invadir el discurso poético. (Ver anexo II).

En este poema, una vez más, son los verbos los que propician la progresión espacio-temporal, generada por un impulso de búsqueda, a partir de su repetición: j'avance, je m'avance, je vais posant. . . construcción, ésta última, que marca perfectamente el aspecto durativo. Verbos que, por otra parte, construyen una dinámica poemática sustentadora de la estructura metafórica que, de nuevo, tiende a la congelación del movimiento, a la solidificación de lo inmaterial, todo lo cual se resume -como en el poema visto anteriormente- en una metáfora que implica espacio y tiempo:

et ne laisse après moi qu'un reste de vertige qui difficilement au loin se cicatrise.

Se aprecia aquí perfectamente la importacia de los deícticos -elementos lingüísticos referidos a la instancia de la enunciación y a un coordenadas espacio-temporales«après moi» $\mathrm{y}$ «au loin» que implican evidentemente un recorrido espacial. Aparecen aquí de nuevo unos ejes temáticos principales de la poesía superviliana connotadores de la temporalidad a través de su «prise de chair» metafórica: la herida y, por metonimia temporal, la cicatriz. (Recordemos esa blessure blanche et bruissante» del poema anterior).

En la segunda estrofa de este segundo poema el cielo ejerce un papel determinante como espacio cósmico a explorar, personalizado siempre en un juego de transgresiones clasemáticas $^{9}$ entre lo animado y lo inanimado, y eje de una imagen por la que se establece un proceso de gigantización primero, y un proceso de reducción, después. En efecto, a partir de la pérdida de la localización espacial («seul égaré dans l'espace») se origina el segundo movimiento, inverso respecto al anterior, por el que el cielo materializado adquiere tamaño humano en función de una reducción de lo infinito a

\footnotetext{
${ }^{9}$ La transgresión clasemática supone la alteración en las relaciones del clasema, entendido éste como subconjunto de semas genéricos (Pottier) o como conjunto de semas contextuales, configuradores de la isotopía (Greimas).
} 
realidades tangibles, a través de la imagen de la bóveda celeste-copa invertida: «Et m'enfonce voûté dans la céleste mine».

Este proceso de reduccción del universo a dimensiones humanas, así como de interrelación de macro y microcosmos, se convierte en una constante de la última parte de la obra superviliana, dominada por un proceso de miniaturización del cosmos. Es lo que se anuncia ya en la identificación metafórica de los versos 5 y 6 entre «voix» y «oiseau» a través del «comme», identidad que se produce también en lo espacial «dans ma tête» - «dans une cage» y que origina sintácticamente un quiasmo perfecto. Se produce así una progresión metafórica entre «voix» y «oiseau» que desemboca en una metamorfosis inacabada: «un oiseau presque humain». Identificación que nos volveremos a encontrar de manera casi idéntica en el tercer poema elegido.

Este es, ciertamente, el primer paso hacia la introducción del cosmos en el espacio carnal del hombre, consecuencia lógica de esa miniaturización del universo que domina toda la última parte de la obra superviliana y que responde al doble proceso de gigantización del hombre, de expansión y de ruptura de sus límites carnales y, por tra parte, un proceso inverso, de repliegue sobre sí mismo y de interiorización del universo por el que se construye un perfecto isomorfismo entre el hombre y el cosmos. El primer proceso obedece al esquema de lo que Jean Burgos denomina «régimen de conquista», primer tipo de sintaxis del imaginario por el que: ${ }^{10}$

«remplir tout l'espace, c'est occuper tout entier le présent, c'est arrêter le temps, le figer là où il est, là où nous sommes, l'empêcher d'aller pus loin, toujours plus loin, et de nous entraîner avec lui. L'écriture de la révolte, qui procède d'un tel schéma directeur, va donc être una écriture de l'espace plein ou en voie de l'être et une écriture cherchant à s'inmobiliser dans le présent»

Ello contribuye, asimismo, a explicar esa aparente contradicción observada en el poema superviliano: el desfase existente entre los elementos propiamente narrativos del texto, que implican una dinamicidad total y obedecen al archisemema de «movimiento» y, más profundamente de «búsqueda», y los elementos figurativos y metafóricos, que obedecen al archisemema «estatismo» y solidificación», y que conducen a la fijación del tiempo a través de su espacialización. Quizás esta dicotomía obedezca también a esa doble vertiente que, según Italo Calvino en Seis propuestas para el próximo milenio ${ }^{11}$ se da en la Literatura, esto es, una tendencia a la levedad, al movimiento, y una tendencia al peso, a lo estático. ¿Responde ello acaso en la poesía de Jules Supervielle a la realidad que fluye y al deseo que la pretende aprehender? ¿Nos encontramos así en el poema superviliano con dos estructuras coexistentes y contrapuestas, pero que responden a la dualidad realidad-deseo? Existe ciertamente, en virtud de la oposición movimientoestatismo, una contradicción entre la estructura narrativa y la estructura metafórica. En ésta última, el sustantivo resulta portador de la carga material, substancial, del poema, el «cuerpo sensible» de la imagen, que responde a ese afán de huir de la nada, del vacío,

${ }^{10} \mathrm{~J}$. BURGOS, Pour une poétique de l'imaginaire, Paris, Seuil, 1982, p. 156.

${ }^{11}$ I. CALVINO, Seis propuestas para el próximo milenio, Siruela, Madrid, 1989. 
de la ausencia, tendiendo siempre a la «concretización» de nociones abstractas y psíquicas por medio del elemento geológico, y al a encarnación de las pulsiones más íntimas del hombre a través del elemento animal.

Por su parte, el verbo agiliza y dinamiza esta materia substantival, confiriéndole capacidad transformadora, según se aprecia perfectamente en el tercer poema elegido, que se inscribe en la segunda gran tendencia ya aludida, aquella que se adentra por las profundidades del cuerpo humano, desvelando no sólo una profundidad física, sino también psíquica, en consonacia con la profundidad cósmica anteriormente recorrida. este es el caso de «Quand le cerveau gît dans sa grotte» (Le corps tragique, 1959), cuyos primeros versos presentan ecos intertextuales baudelairianos (recordemos ese «Quand le ciel bas et lourd pèse comme un couvercle».. .), organizándose según un rígido paralelismo sintáctico en función de las oraciones circustanciales temporales en la primera parte, y de las subordinadas de relativo, en la segunda. (Ver anexo III).

Elpoema se construye en función de una constante de «movimiento», archisemema que domina la estructura metafórica del poema a través de los sememas «chauvesourient» («murcielaguean», neologismo de cosecha superviliana creado a partir de la catálisis animal) y «fourmillent» (indicativo del movimiento desordenado, de la agitación, del "grouillement»). Así como de la constante de «transformación» reflejada en los sememas «devenir» (que implica el paso de un estado a otro, la transformación de la materia) y «grandin», «s'accroître» (sememas que indican una modificación del tamaño).

Como en los poemas anteriores, son los verbos, junto con los modificadores adverbiales, los que marcan la progresión tanto narratológica y evenemencial como semántica, propiciando en éste último poema el tránsito de lo mental a lo animal, y de lo animal a lo cósmico, tránsito representativo de la dinamicidad metafórica del poema superviliano, en el que las pulsiones psíquicas o anímicas se encarnarán preferentemente en el elemento animal, mediador entre el hombre y el cosmos.

De este modo, el devenir del poema implica el paso que diferentes ámbitos de la realidad, devenir procurado no sólo por el semantismo verbal, sino también por la serie de transgresiones clasemáticas que lo constituyen, siendo el elemento humano el punto de partida y de llegada, como puede apreciarse en los dos primeros versos de este tercer poema, («cerveau - grotte - chauve-sourient - pensées») en los que aparecen ya las dos isotopías dominantes: pensamientos y obsesiones por un lado, bestiario, por otro; anecdódica la primera, metafórica la segunda, y que progresivamente invade la totalidad del poema, produciéndose así una animalización de las pulsiones mentales interiores. $\mathrm{Y}$, en este caso, la animalización del espacio humano interior conlleva un movimiento progresivamente acelerado, expresado por medio de las repeticiones «vous hantent, vous hantent / jusqu'à devenir chats-huants», juego de palabras que, además de contribuir a introducir lo humorístico en el discurso trágico, hacen referencia a una de las constantes de la poesía superviliana no sólo en el nivel formal, sino también en el nivel temático: la transformación o metamorfosis.

Esta constante presenta a nivel textual importantes consecuencias en la introducción del discurso narrativo en el poema, en tanto que expansión y desarrollo metafóricos que, si bien no abarca sistemáticamente la totalidad del poema, si ofrece fugas dinámicas, 
constituyendo microsegmentos narrativos con autonomía propia. Los últimos versos de un poema de Gravitations titulado «Apparition»: nos ofrecen un claro ejemplo: ${ }^{12}$

Nous cueillons et recueillons du céleste romarin,

De la fougère affranchie qui se passe des racines,

Et comme il nous est poussé dans l'air pur des ailes longues,

Nous mêlons notre plumage à la courbure des mondes.

Ejemplo que pone claramente de manifiesto, por un lado, el paso de lo humano a lo animal, transformación en hombre-pájaro indicada sinecdóquicamente por «aile» y «plumage» y por otro, la pérdida de los límites corporales en virtud de la adquisición de un tamaño cósmico, de un proceso de gigantización a medida del universo.

El poema superviliano parece en efecto responder a la sugerencia de René Char en Feuillets d' Hypnos: «L'Heure est propice aux métamorphoses: mettez-la à profit ou allez-vouz en ${ }^{13}$. De tal manera que la metamorfosis constituye uno de los vectores principales de su quehacer poético, según se explicita en su metadiscurso literario:

«L'état de poésie me vient alors d'une sorte de confusion magique où les idées et les images se mettent à vivre, abandonnent leurs arêtes, soit pour faire des avances à d'autres images soit pour subir de profondes métamorphoses qui les rendent méconnaissables» ${ }^{14}$.

¿Qué supone realmente la introducción de este elemento metamórfico en el discurso poemático? Creemos que, independientemente del hecho de conferir un dinamismo interno al poema, esta metamorfosis constituye la explicitación o el desarrollo narrativo de la síntesis metafórica.

En realidad, la metáfora no es más que la expresión sintética del proceso metamórfico, en virtud del cual se produce una transmutación de las cosas y de los seres entre sí, y no necesariamente en virtud de un analogía racional o por razones de contigüidad, sino de manera arbitraria, subjetiva e irracional, según los fundamentos de la poeticidad moderna que, como dice L. Aragón, «obliga a revisar todo el Universo».

La metáfora es ya metamorfosis implícita que en modo alguno intenta reproducir la realidad, sino que produce una nueva realidad a través de una interacción lingüística de sus elementos, a través de la presencia simultánea de los dos elementos constitutivos. Según afirma Jean Molino ${ }^{15}$ :

«Grâce à une vision stéréoscopique qui nous oblige à regarder deux termes en un seul coup d'oeil, nous opérons une redescription du monde et acquérons de nouvelles connaissances. La relation qui existe entre les deux termes a donc une présomption

${ }^{12}$ SUPERVIELLE, J. Gravitations, Paris, Gallimard, 1946.

${ }^{13}$ R. CHAR. Feuillets d' Hypnos, Paris, Gallimard, 1946.

${ }^{14}$ SUPERVIELLE, J. En songeant d un art poétique, o. c. 64.

${ }^{15}$ J. MOLINO, «Problèmes de la métaphore», in Langages 54, Paris, Larousse, 1979, p. 23. 
de fondement ontologique, en ce qu'elle peut nous révéler quelque chose de la structure du monde, de la structure de notre être propre, et des rapports entre le monde etnous-même, entre le microcosme humain et le macrocosme que constitue l'univers"

Si en la metáfora ello produce una visión «estereoscópica» que obliga a representar simultáneamente esas dos realidades se presentan sucesivamente a partir de un desarrollo espacial y temporal explicitado textualmente.

Si tomamos la metáfora in praesentia por atribución «la terre est une quenouille que filent lune et soleil», el paso del semema A (terre) al semema B(quenouille) se realiza implícitamente por medio de algunos semas comunes, esto es, por lo que se refiere a su movimiento giratorio. Se produce, así un cambio, una transformación de la materia lingưística por la que se parte de la clase semántica de lo cósmico geológico para llegar a la de lo material objetal. Por lo tanto, la metáfora contiene en sí misma ese proceso metamórfico, que supone ineludiblemente una transformación de la substancia poética. Y no sólo la metáfora, sino también la comparación, como en este bello ejemplo que nos proporciona Le forçat innocent ${ }^{16}$ :

«Le soir, ses lentes paupières

Comme un oiseau près de mourir

Qui lui jeta la grave pierre

Par où coule déjà la nuit».

Comparación en la que el atardecer se convierte en un pájaro languideciendo, con una temporalidad implícita a través del adjetivo «lentes».

La explicitación del proceso metamórfico en el texto poético supone la inclusión de un esquema narrativo que procura el trayecto comprendido entre un elemento $\mathrm{A}$ y un elemento B, que no coexisten como en la metáfora, sino que se suceden.

Es el caso del cabritillo que se convierte en estrella merced a un movimiento vertiginoso: «Un chevreau tournant sur soi jusqu’à devenir une étoile» o de ese «écureuil que devient feuille et bois dans sa fuite». Dinamicidad que, en el caso del último poema elegido, "Quand le cerveau gît dans sa grotte», adquiere connotaciones negativas en función de la metamorfosis animal.

Hay, por lo general, una negatividad implícita en la animalización del universo porque, como dice Gaston Bachelard a propósito de Lautréamont: «la vie animalisée est la marque d'une richesse et d'une mobilité des impulsions subjectives. C'est l'excés du vouloir-vivre qui déforme les êtres et qui détermine les métamorphoses» ${ }^{17}$.

La poesía de Supervielle hereda esa dinamicidad vital que también se manifiesta a través de la animalidad, tendencia que supone la representación de las tensiones internas del hombre, en las que se adivina una agresividad refrenada, una violencia contenida. Así tenemos al final del libro de poemas Gravitations un texto en el que el

${ }^{16}$ J. SUPERVIELLE, Le forçat innocent, Paris, Gallimard, 1934.

${ }^{17}$ G. BACHELARD, Lautréamont, Paris, Corti, 1939, p. 12. 
yo termina convirtiéndose un rinoceronte, colmando así el desorden psicológico interior ${ }^{18}$.

El estudio de los relatores temporales nos revela asimismo la constante de rapidez: «tout d'un coup», «tout de suite», «subitement», «vite», etc. Efectivamente, la metamorfosis se produce por lo general de manera súbita y casi inesperada. El tiempo es vivido como cúmulo de instantes decisivos, como sucesión vertiginosa de estados transitorios, pero en otros casos, los menos en la poesía superviliana, como desarrollo sin fin de transiciones lentísimas que nos recuerdan al Grégoire Samsa kafkiano.

La poesía de la metamorfosis constituye, pues, una poesía en devenir, en constante proyección, en la que los objetos y seres del universo resultan intercambiables. Se revela así como una función específica y característica de la imaginación poética en la que se hallan implicados materia, espacio, tiempo y movimiento, contribuyendo a introducir una dinamicidad en el mecanismo metafórico y abarcando, si no el poema entero, sí verdaderos microsegmentos textuales.

Ello resulta, por otra parte, de un sentimiento de precariedad existencial, de inseguridad ante la movilidad del universo que dominará la totalidad de la obra superviliana. Porque, como dice el poeta en la sección «Métamorphose» de Le corps tragique:

«Chacun a toujours en lui

De quoi devenir autrui

Et peut par vent favorable

Naviguer vers d'autres fables» ${ }^{19}$

Se evidencia así la percepción del mundo en «levedad», representada en la estructura narrativa del poema, frente a la volutad de representación en peso, densidad, corporeidad, substancialidad como es el caso del procedimiento propiamente metafórico en el poeta estudiado. Ello puede obedecer al intento de encontrar las leyes de permanencia a través de la percepción confusa de un universo en constante movimiento y cambio bajo el cual se adivina una cierta unidad y permanencia, porque, quizás, como dice René Char: «Si nous habitons un éclair, il est au coeur de l'éternel» ${ }^{20}$.

Además de ese sentimiento de precariedad existencial otros dos vectores temáticos rigen la introducción del proceso metamórfico en la poesía superviliana: por un lado, las transformaciones que procura el universo onírico, con lo que Supervielle conecta directamente con una de las grandes preocupaciones del surrealismo contemporáneo.

Agente onírico de la metamorfosis explicitado en los versos siguientes, en los que se ponen asimismo de manifiesto dos de las constantes anteriormente vistas: la mediación metafórica del bestiario en el proceso de transformación, y la existencia de

\footnotetext{
${ }^{18}$ Algo que, evidentemente, recuerda al Rhinocéros de Tonesco, con el que las similitudes son grandes.

19 J. SUPERVIELLE, Le corps tragique, Paris, Gallimard, 1959. p. 74.

${ }^{20}$ R. CHAR, Les Matinaux, Paris, Gallimard, 1969, p. 49.
} 
ese universo interior del hombre, albergando todo el espacio exterior con su carga de infinito $^{21}$ :

Dès que nous sommeillons

Tous devient animal, Oiseaux, chiens et poissons

Sans nous faire de mal

Parcourent notre monde

Mince mais infini»

$\mathrm{Y}$, por otra parte, las transformaciones que conlleva el recuerdo y su representación a través de una memoria traidoramente «olvidadiza» (recreadas en el poema magnífico de «Oublieuse mémoire»), con lo que Supervielle se aproxima a otro de los grandes temas contemporáneos: el recuerdo y el mecanismo de la memoria, siguiendo las pautas marcadas por $\mathrm{H}$. Bergson algunos años antes.

Metamorfosis conseguida ante todo, finalmente, por el poder mágico de la imaginación, encarnación de un deseo que alcanza su plenitud gracias a la palabra. Queda así de manifiesto cómo la metamorfosis constituye, en definitiva, una expresión siempre de las profundidades del inconsciente que se encarna en la imaginación creadora y que, explicitada lúcidamente como tal, se desarrolla en el hilo narrativo del poema a partir de una matriz metafórica.

\section{Anexo I}

Comme un boeuf bavant au labour

Le navire s'enfonce dans l'eau pénible, la vague palpe durement la proue de fer, áprouve sa force, $s$ 'accroche, puis déchirée, s'écarte, à l'arrière la blessure blanche et bruissante, déchiquetée par le hélices, s'étire multipliée et se referme au loin dans le désert houleux où l'horizon allonge ses fines, fines lèvres de sphinx.

Le deux cheminées veillant dans un bavardage de fumée, le paquebot despus dix jours, avance vers un horizon monocorde que coincide sans bavures avec le horizons précédents et vibre d'un son identique

${ }^{21}$ J. SUPERVIELLE, Compagnons du silence, Paris, Flory, 1939, p. 20. 
au choc de mon regard que se sépare de moi, comme un goéland, du rivage. $\mathrm{O}$ mer qui ne puise en soi que ressemblances, et qui pourtant de toutes parts s'essaie aux métamorphoses, et vaine, accablée par sa lourdeur prolifère, se refoule, de crête en crête, jusqu'au couperet du ciel, mer renaissante et contradictoire, présence fixe où hier tomba un mousse détaché d'un cordage comme par un coup de fusil, présence dure qui, la nuit, par delà les lumières du bord et la musique cristalline, et les sourires des femmes, et tout les le navire, rêves et bastingage, vous tire par les pieds à six mille mètres de silence où l'eau rejoint une terre aveugle pour toujours dans un clame lisse et lacustre, sans murmures; O mer, qui fait le tour du large, coureur infatigable, quelle nouvelle clame-t-elle dans l'atmosphère avide où ne pousse plus rien, -pas une escale, pas un palmier, pas une voile,comme après une déracinnante canonnade?

J. Supervielle, Débarcadéres, (1922)

\section{Anexo II}

\section{Sans Dieu}

J'avance entre les astres avec deux chiens aveugles

Qui parfois se repprochent pour chercher mon chemin.

On ne voit rien ici que ressemble à la Terre

Mais une odeur saline à mes lèvres parvient

Et j'entends une voix qui tourne dans ma tête

Comme dans une cage un oiseau presque humain.

Mon coeur de chaque jour, ici noire est l'aurore,

Veut en vain s'allumer sous le ciel qui déborde.

Le givre de la nuit paralyse l'éther,

Je m'avance et me sens mille fois découvert.

Prêtant le flanc, le dos, la tête et la poitrine

A tous les dards de l'Inconnu qui m'avoisine. 
Je vais posant les pieds sur un sol nuaguex

Où mes yeux ne voient pas les empreintes de Dieu

Et ne laisse après moi qu'un reste de vertige

Qui difficilement au loin se cicatrise.

Autour de moi les mains errantes des amis

Sentant que je suis seul égaré dans l'espace

Me cherchent sans pouvoir trouver l'exacte place

Et repartent au large vers la Terre qui fuit.

La feuille d'un palmier privé de ses racines,

Murmure à mon oreille une chanson sans suite.

Le ciel tout près de moi me tourmente et me ment,

Il m'a pris me deux chiens gelés restés derrière,

Et j'entends leur exsangue, immobile aboiement,

Les étoiles se groupent et me tendent des chaînes.

Faudra-t-il humblement leur offrir mes poignets?

Une voix qui voudrait faire croire à l'été

Décrit un banc de parc à ma fatigue humaine.

Le ciel est toujours là qui creuse son chemin,

Voici l'écho des coups de pic dans ma poitrine.

O ciel, ciel abaissé, je te touche des mains

Et m'enfonce voûté dans la céleste mine.

Jules Supervielle. Le forçat innocent. 1930

Anexo III

Bestiaire Malfaisant

Quand le cerveau gît dans sa grotte

Oú chauve-sourient les pensées

Et que le désirs pris en faute

Fourmillent, noirs de déplaisir,

Quand les chats vous hantent, vous hantent

Jusquà devenir chats-huants,

Que nos plus petits éléphants

Grandissent pour notre épouvante,

$\mathrm{O}$ bestiaire malfaisant

Et qui s'accroît chemin faisant,

Bestiaire fait de bonnes bêtes 
Qui nous paraissaient familières

Et qui tout d'un coup vous secrètent

Un univers si violent

Que, le temps de le reconnaître,

Nous n'en sommes déjà plus maîtres.

Il nous fige et va galopant

Autour de nous dans tous les sens

Ainsi qu'une aveugle tempête

Qui ne se trouve qu'en courant.

Jules Supervielle, Le corps tragique, 1959 